\title{
ESCRITOS MAYAS INÉDITOS Y PUBLICADOS HASTA 1578: TESTIMONIO DEL OBISPO DIEGO DE LANDA ${ }^{1}$
}

\author{
René Acuña
}

Centro de Estudios Mayas

\begin{abstract}
AвsтrAct: Bishop Landa was one of the major actors, and actually authors, in sixteenth century Yucatan. Importance of his letter, addressed to the Inquisidores of New Spain (Jan. 19, 1578), stands is that he explicitly explains what the status of the Maya written production by the Franciscan friars was by that time. He does not mention any existing grammar and/or Mayan vocabulary, and he roundly denies that Maya translations of the Holy Books were then available. Presentation of Landa's letter is a brief one, with no claim whatsoever to historical and/or philological depth.
\end{abstract}

Resumen: El obispo Landa fue uno de los principales actores, de hecho autores, en el Yucatán del siglo xv. La importancia de su carta, dirigida a los inquisidores de Nueva España (enero 19 de 1578), radica en que expone sin reticencias el estado en que se encontraba la producción de los lingüistas franciscanos hasta la época de su informe. Sobre la existencia de gramáticas o vocabularios de lengua maya no dice palabra, y sin ambages niega que hubiera a mano traducción alguna de las Escrituras Sagradas. La presentación de esta carta es sumaria, sin la menor pretensión de profundidad filológica o histórica.

\section{El manuscrito, descripción y datos históricos}

El documento publicado a continuación se encuentra en el Archivo General de la Nación $(\mathrm{AGN})$, ramo Inquisición, volumen 90 , expediente 42 (antes 8 ). Consta de dos fojas tamaño folio, escritas por ambas caras. Las tres primeras planas contienen la carta que el obispo de Yucatán, don Diego de Landa, dirigió a los señores inquisidores apostólicos de la Nueva España, con sede en México, el 19 de enero de 1578; la cuarta y última plana, el sobrescrito y algunas anotaciones fueron hechas por un cu- rial del arzobispado. La carta en sí consta de 84 líneas, cada una con un promedio de 11 palabras, lo cual resulta en un texto aproximado de 924 palabras.

Excluidas las inscripciones modernas que identifican el documento en el $\mathrm{AGN}$, el escrito acusa la intervención de cuatro amanuenses, tres de ellos anónimos: el designado por Landa para escribir la carta, y dos curiales del Santo Oficio. El primer oficial anotó la fecha de recepción del escrito en la esquina superior izquierda de la primera plana; el segundo redactó un resumen del contenido en el dorso del sobrescri-

\footnotetext{
${ }^{1}$ Agradezco cordialmente las correcciones y finas recomendaciones de Carmen León Cázares, y la considerada revisión defAnalibuisa dzquierdpaya. Vol. XXI, 2000 
to. El cuarto amanuense fue el obispo Diego de Landa, quien, tras firmar, añadió de su propia mano una posdata de cuatro líneas. Sorprenden los laboriosos y firmes trazos de su caligrafia. Anticuada tal vez, pero muy clara y legible. El experto hará bien en cotejar las de Landa con letras latinas de los siglos xIv y xv.

Las referencias veladas a personajes históricos, sin conocer los cuales hallará el lector varios pasajes oscuros, pueden resumirse de la manera que sigue: don Pedro Moya de Contreras, inquisidor apostólico desde 1570 , gobernaba el arzobispado de México desde 1574. Aunque su nombre no se mencione, a él en primer lugar está dirigida la carta de Landa. Sin duda se conocían personalmente. Landa había residido por varios meses en la ciudad virreinal, desde el segundo semestre de 1574 hasta $1575,^{2}$ a fines del cual regresó a su diócesis. Así lo atestigua su carta de 20 de diciembre de dicho año, en que manifiesta:

Yo truxe de España, allende de encomendada muy encargada por su Magestat, esta provincia de Tabasco y la visita della. Y así me determiné, después que salí de esa cibdad de México, de visitarla toda antes que <me > volviese a la provincia de Yucatán... (Landa, 1959: 171, doc. 5; el subrayado es mío).

El recién llegado (llegó en 1577) gobernador de Yucatán, al que el seráfico obispo alude en su posdata, era don Guillén de las Casas. Antes de pasar no sabemos si a "mejor vida" en abril de 1579 , Landa tendría con él fricciones bastante serias y varios dimes y diretes (véase Lizana, 1995: 192-199). Es manifiesto que el franciscano desaprobaba que el nuevo gobernador hubiera elegido por confesor al deán de la cate- dral y comisario del Santo Oficio, tampoco mencionado por su nombre. Se trata del licenciado Christóbal de Miranda, nombrado para ese cargo desde el 15 de octubre de 1549, 13 años antes de que el primer obispo efectivo, fray Francisco de Toral, ciñera la mitra de la diócesis yucateca. Miranda presidió el cabildo catedralicio durante las vacantes que ocasionó la muerte de Toral en 1571 y la del propio Landa en 1579. Debió fallecer en la década de los ochentas, sin duda antes de 1587 (véase Rubio Mañé, 1957: 486, 488, 490).

El otro sujeto con quien fray Diego traía pique, pero al que nombra en todas sus letras, es don Diego de Santillán. Éste había sido gobernador de Yucatán entre 1571 y 1573.

Estando en el gobierno de Yucatán se enamoró nada menos que de doña Beatriz de Montejo, la viuda de Montejo el Sobrino. Era encomendera de los pueblos de Chuburna, Hunucma, Tixkokob, Nolo, Mococha y Buctzotz. Parece que hubo pleitos para ganar la mano de doña Beatriz, porque tenía varios pretendientes, entre ellos un sobrino del obispo fray Diego de Landa, a quien quería casar con la viuda, y con tal objeto lo trajo de España; pero llegó tarde. Fray Diego de Landa arribó a Campeche el 11 de octubre de 1573 para tomar posesión como obispo y en su compañía trajo al sobrino. El gobernador casó con doña Beatriz en Mérida el 16 de septiembre de 1572... (Rubio Mañé, 1957: 465, n. 18).

La nota de Jorge Ignacio Rubio Mañé, que acabo de citar apenas en parte, abunda en datos sobre Diego de Santillán. Su lectura se recomienda a quien desee mayor información sobre el feliz pretendiente, ex gobernador y encomendero más tarde. El final de esa historia es, sin embargo, más bien patético.

\footnotetext{
${ }^{2}$ Que Landa se encontraba fuera de su diócesis a finales de 1574 parece comprobado por el hecho de que el gobernador Velásquez de Gijón informó en diciembre de dicho año al deán catedralicio de Mérida, Cristóbal de Miranda, "administrator of the diocese in the absence of Bishop Landa" (Scholes y Roys, 1968: 224), sobre los efectos de la expedición encomendada a Felicjano Bravo.
}

Instituto de Investigaciones Filológicas/

Centro de Estudios Mayas, UNAM 


\section{Escritos mayas en 1578}

Si uno lee la excerpta que redactó el curial del arzobispado de México, tiene que admitir que ese tinterillo anónimo, sin alharacas ni pretensiones de presentar un análisis espectral, hizo un aceptable resumen de la carta de Landa. Concedió el primer lugar a la "traductión de Scriptura sagrada en lengua de los naturales de aquella tierra". Es el tema que aquí interesa y que ha motivado esta publicación.

Será punto de partida el testimonio que dejó Landa en lo que ahora se llama Relación de las cosas de Yucatân, cuyo manuscrito (un traslado tardío) se encuentra en la Biblioteca de la Real Academia de la Historia, en Madrid (sig. [24-B68] 9-27-2/5153):

...Y que, después, fray Toribio Motolinea embió desde Guatimala frayles, y que, de México, fray Martín de Hojacastro embió más Indios, y que todos tomaron assiento en Campeche y Mérida, con favor del Adelantado y de su hijo don Fran $<$ cis $>\mathrm{co}$, los quales les edificaron vn monesterio en Mérida, como está dicho. Y que procuraron saber la lengua, lo qual era muy dificuloso [sic]. El q<ue> más supo fue fray Luys de Villalpando, que comenzó a saberla por señas y pedrezuelas, y la reduxo a alguna manera de arte, y escrivió vna doctrina Christiana en aquella lengua (fol. 13r).

Hay que aclarar, sin embargo, que Motolinía, según propio testimonio:

...fray Luis de Villalpando, y otros, me pidieron muchas veces licencia para ir a Yucatán, y yo no se la dando, procuráronla del que a mí me envió, que es nuestro superior (carta fechada en Suchitepec, Guatemala, a 21 de octubre de 1545; en Vázquez, 1937, 1: 106),

jamás "embió desde Guatemala frayles". Debió autorizar suEsviajes dentonces,Iafnay oMartín 2 de Instituto de Investigaciones Filológicas/ Centro de Estudios Mayas, UNAM ISSN: 0185-2574
Hojacastro, quien, tras el fallecimiento de fray Jacobo de Testera en 1542, le sucedió en el cargo de comisario general. Los frailes que salieron de Guatemala con Villalpando llegaron a Campeche hacia finales de 1545 . La ciudad de Mérida había sido fundada por Francisco Montejo, hijo, desde 1542. La construcción del convento de San Francisco se inició en 1547, fecha en la cual Hojacastro es nombrado obispo de Tlaxcala, y se concluyó en 1561. Cae más allá de toda posible aclaración que este fraile haya enviado a Yucatán "más Indios"; pero el interesado hará bien en leer el comentario de Tozzer (1941: 68, n. 308) a esta frase.

$\mathrm{Y}$ ahora el punto que nos importa. Obsérvese que Landa es muy cuidadoso al referirse al trabajo lingüístico de Villalpando. Por una parte explica que fray Luis "reduxo <la lengua maya $>$ a alguna manera de arte" y, por otra, que "escrivió vna doctrina Christiana en aquella lengua", posiblemente la misma que él hizo publicar en México, en 1575, durante su breve estadía en esta ciudad. Pero, ¡mucho ojo! con este dato. Entre reducir una lengua "a alguna manera de arte", y componer y escribir un arte gramatical de esa lengua, hay una sutil diferencia. Por no haber reparado en ella, varios estudiosos modernos han saltado a la conclusión de que Villalpando compuso un Arte de la lengua maya, cuyo manuscrito se ha extraviado (véase Tozzer, 1977: 151, 274).

Más aún, apoyados en un pasaje de López de Cogolludo, quien a su vez se inspiró en Lizana (1633), han llegado a sostener que el presunto Arte de Villalpando fue perfeccionado por Landa. Otros, más fantasiosos, han afirmado que Villalpando compuso también un Vocabulario maya, y que éste ¡se imprimió en México en 1571! (véase García Icazbalceta, 1954: 41, n. 107), casi 20 años después de haber fallecido su autor. El pasaje de López de Cogolludo que he mencionado arriba, es el siguiente: 
Bolvió de España [1560] el bendito Padre Fr. Lorenço de Bienvenida..., y traxo vna Missión de diez Religiosos, que le dió el Rey para esta Prouincia... El R. Padre Custodio dió orden al Padre Fr. Diego de Landa, que era Guardian de Merida, para que fuesse al Puerto <de Zilam>, y los recibiesse, y lleuandolos al Conuento de Ytzamal les leyesse el Arte de la lengua de estos naturales, que él auia perficionado, y en sabiendole se fuesse à su Conuento de Merida (López de Cogolludo, 1688: 308a; itálicas mías).

Muy bien. Pero el razonamiento de los peritos (véase Tozzer, 1941: 69, n. 313) se basa, aquí, en la interpretación estrecha de lo que significa "leerles el Arte de la lengua de estos naturales", que no es la grosera de "leerles un libro ni algo que está manuscrito", sino la de "aleccionarlos" o "enseñarles la lengua". De ahí que, otra vez, Tozzer (1977: 151, 244) coloque en su lista de missing autborities un fantasmal Arte escrito por Landa, "possibly a revised edition of Villalpando".

Para aclarar un poco este enredo, que ha adquirido aires y apariencia científicos, puede servir la carta de Landa aquí publicada. Ella no avala esas especulaciones. El seráfico fraile, que no desperdicia ocasión para insinuar o francamente poner de relieve sus méritos, dice en 1578:

En esta tierra no se a, hasta aora, traduzido en la lengua de los naturales cossa alguna de la Sagrada scriptura, ni tienen en la lengua más de vna Doctrina christiana $\mathrm{q}<\mathrm{ue}>$ yo hize ymprimir en essa çiudad, estando en ella. Y, también, algunos sermones de mano en la mesma lengua, no ympressos. Y de éstos, porque e yo hallado algunas cossas que me an descontentado en algunos, abía ya días que los andaba haziendo recoxer para examinarlos y ver si tienen que les quitar... El <orden> que por acá aora ay, es predicar cada vno conforme a las fuerças que en la lengua y en la suffiçiençia tiene..E(currsivas mías)a Maya. Vol. XXI, 2000

Instituto de Investigaciones Filológicas/

Centro de Estudios Mayas, UNAM ISSN: 0185-2574
Y nada más. El obispo Landa, uno de los protagonistas y testigos más connotados de la conquista espiritual de Yucatán, de la historia lingüística y literaria de esa región, nada dice aquí de artes gramaticales ni de vocabularios, impresos o no.

Naturalmente, cabe argüir que el testimonio de Landa concierne sólo a textos doctrinales, porque ésos eran los que podían interesar a las autoridades del Santo Oficio. Pero la relativa fuerza de este argumento se desvanece, si uno recuerda que todas las obras escritas en lengua indigena, doctrinales por título o no, estaban sujetas a la censura y examen del Consejo Inquisitorial. Un arte gramatical, un inocente vocabulario, podian proponer palabras y verbos que afectaban de manera profunda a la teología cristiana. Para citar un ejemplo entre muchos, Varea ( $f$ l. 1593), en su Calepino en lengua quiché (manuscrito: 325), advierte al posible usuario:

Para dezir ellos una persona, dos personas, dizen bun, cay chi vinak, q<ue>, en propriedad de su lengua, sig<nific $>a$ "una gente, dos gentes". Y, assí, no se debe poner esta palabra en el Misterio de la SS. Trinidad, porq<ue> es nombre copulativo, y tiene diversas y ambiguas significaciones, como diré después.

Y no hay para qué recordar, porque son de todos sabidas, las enconadas polémicas teológicas que, en el siglo xvi, ocasionó la simple palabra Dios traducida a lenguas indígenas. Pero, minucias aparte, las artes de lengua, y sobre todo los calepinos, a título de frases ilustrativas traducían pasajes de la Sagrada Escritura, como debe saberlo el que haya leído con atención el Calepino maya de Motul (unam, 1984), cosa severamente prohibida en aquella época. Más aún, muchas artes gramaticales se acompañaban con nociones doctrinales cristianas, lo cual las dejaba asaz vulnerables a acusaciones e insidias de 
intérpretes malintencionados o suspicaces. Tal fue, por citar un caso, lo ocurrido en 1744 al Arte de la lengua mexicana (1717) de fray Francisco de Ávila (León Rivera, 1996: 245-252).

\section{La doctrina de 1575}

García Icazbalceta (JGI, 1954: 485, n. 38) dedica estas breves líneas a la Doctrina cristiana en lengua maya publicada por Landa:

Medina, $I M$, I, núm. 200 d, p. 378.-Wagner, Nueva bibliografia, p. 497.-Zulaica, Los franciscanos, núm. 52 , p. 177 , con exposición de los argumentos para fijar la impresión de este libro en 1574-75. Subsiste siempre la posibilidad de que haya salido de alguna imprenta española.

Los argumentos de Zulaica Gárate (1991: 177 , n. 52) descansan en tres cartas de Landa publicadas por Pérez Martínez como apéndices documentales 3-5 de la Relación de las cosas de Yucatân (1938; véase edición de Garibay, 1959: 166-172). La primera (doc. 3), datada en Mérida Yucatán a 22 de marzo de 1574 , pone de manifiesto que el obispo se encontraba entonces en su diócesis; la segunda, que publicamos aquí, se refiere a la Doctrina christiana que él había hecho imprimir en la ciudad de México, "estando en ella"; la tercera (doc. 5), datada en "Xalapa Zavatan provincia de Tabasco" a 20 de diciembre de 1575, atestigua que Landa iba de regreso a su diócesis después de haber estado en la ciudad virreinal durante varios meses. $\mathrm{Zu}$ laica Gárate (loc. cit.) concluye: "Por lo cual, hay que fijar la fecha de la impresión de su doctrina entre la segunda mitad del año 1574 y la primera de $1575^{\circ}$. Frente a esta argumentación documental y testimonial, la duda de don Joaquín - "subsiste siempre la posibilidad..."- parece irrelevante.

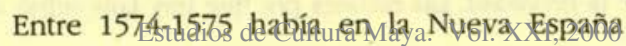
Instituto de Investigaciones Filológicas/ Centro de Estudios Mayas, UNAM ISSN: 0185-2574 tres impresores activos: Pedro Balli, Antonio de Spinosa y Pedro Ocharte. El tercero, sin embargo, desde 1572 estaba embrollado en un serio proceso inquisitorial por proposiciones heréticas (JGI, 1954: 53, 63) y, hasta donde consta, su casa y nombre se eclipsaron por varios años (1572-1578). Nos quedan, entonces, nada más Pedro Balli y Antonio de Spinosa como candidatos posibles para haber dado a la estampa la Doctrina christiana en la lengua maya. La más activa durante este periodo fue la casa de Balli; Spinosa encubrió, al parecer, las actividades de Ocharte (véase JGI, loc. cit.: 66). Considerando lo desconfiado, sensitivo y suspicaz que era Landa en asuntos de Inquisición, yo me inclinaría a pensar que la casa de su elección fue la imprenta de Pedro Balli.

\section{Los "sermones no ympressos"}

Sobre estos "sermones de mano", parece obvio que el buen obispo de Yucatán abrigaba algunos recelos, pues "abía ya días que los andaba haziendo recoxer para examinarlos". Es tal vez gracias a esa acción que muchos de ellos se conservaron, llegando a constituir una especie de corpus que podía ser consultado a principios del siglo xvir. A este respecto, no cabe duda de que varios de los Discursos predicables publicados por fray Juan Coronel en 1620 procedian de este repositorio. La obra, en $8^{\circ}$, consta de 240 folios (= 480 páginas). Un verdadero tesoro literario de lengua maya colonial en espera del editor que sepa leerlo, corregir sus numerosas erratas y traducirlo.

La obra de Coronel, en general poco conocida por los mayistas, consta de tres volúmenes: estos Discursos predicables; una Doctrina christiana, presumiblemente la misma que publicó Landa en 1575, nada más que corregida, y el Arte en lengua de maya. Los tres tomos fueron estampados en México en 1620. El Centro de Estudios Mayas está 
preparando una edición crítica y anotada del Arte, el cual saldrá acompañado por la Doctrina y algunos textos seleccionados del corpus.

Parece pertinente añadir que ese Arte de Coronel, el más temprano dado a la estampa, no registra mención ni referencia alguna a escritos gramaticales previos; aunque, por testimonio de su contemporáneo Lizana, ${ }^{3}$ consta que varios predecesores suyos habían compuesto artes. Artes que, como el mismo de Coronel, tuvieron uso muy limitado en las clases de lengua que impartían los franciscanos a sus novicios. En ese sentido es interesante observar que en 1684, cuando fray Gabriel de San Buenaventura publica su Arte (UnAm, 1996), la obra de Coronel había caído en total olvido. Un hecho tal no se podría explicar, si el único Arte impreso existente hubiera estado en servicio activo en las aulas religiosas.

\section{Las traducciones de la Sagrada Escritura}

Debido al movimiento de Contrarreforma, tan vigoroso en España, la Inquisición mantenía severas restricciones y ojo muy atento sobre las traducciones de la Sagrada Escritura. En general, la Iglesia prohibía su traducción a cualesquiera lenguas vulgares. No obstante su reconocida competencia escriturística y en la lengua hebrea, el agustino y poeta fray Luis de León dio con sus huesos en una cárcel de Valladolid, donde permaneció desde 1572 hasta 1576, por haber traducido al espanol el Cantar de los cantares. ${ }^{4}$

De ahí el cuidado con que el obispo Landa niega de manera rotunda: "En esta tierra no se a, hasta aora, traduzido en la lengua de los naturales cossa alguna de la Sagrada scriptura". Muy bien; pero, si se acepta de buena fe ese testimonio, como tal vez lo hicieron los inquisidores de Nueva España, uno se pregunta sobre qué tratarían los "sermones de mano en la mesma lengua" que el vigilante obispo "abía ya días que los andaba haziendo recoxer". En otras palabras, ¿qué clase de instrucción cristiana impartían los religiosos a sus neófitos yucatecos? En los sermonarios españoles de la época, cuando se cita algún lugar bíblico, se hace en latín. La fidelidad de las citas es harina de otro costal, porque los predicadores adulteraban los textos para ponerlos al alcance de sus oyentes; pero en Yucatán, ¿cuántos naturales entendian latín, así fuera de cocina?

Por otra parte, yo he encontrado numerosos pasajes bíblicos traducidos al yucateco en el Calepino maya de Motul, hecho que permite inferir su preexistencia a la composición de la obra. Dichas citas corresponden, como parece natural que haya sido, a las Epístolas y Evangelios del año; esto es, a los fragmentos que el sacerdote recita en las misas dominicales y de las fiestas mayores. Entonces, dicho sea sin ánimo de ofender la veracidad del prelado Landa, ¿resulta enteramente creíble que en esos "sermones de mano" no se haya "traduzido en la lengua de los naturales cossa alguna de la Sagrada scriptura"? Los hechos que su carta declara, ¿merecen entera fe, o deben considerarse producto de una respuesta cauta de oficio, defensiva y llena de reticencias, sólo para cumplir con el expediente?

\section{Criterios paleográficos de la presente publicación}

La carta de 1578 del obispo Diego de Landa fue publicada, por vez primera hasta donde sé,

\footnotetext{
${ }^{3}$ Véase por favor a este respecto "Lingüistas franciscanos" en el índice analítico de la edición unam, 1995: 323. La obra de Lizana comprende alrededor de 80 años de la historia eclesiástica yucateca, en cuyo lapso recuerda a 25 lingüistas, la inmensa mayoría de los cuales floreció en el último cuarto del siglo xvı.

${ }^{4}$ Aclaro que mi explicación es muy simple por mor de la brevedad. Las razones por que fray Luis sufrió dicho confinamiento fueron varias X más epmplejas.

Instituto de Investigaciones Filológicas/

Centro de Estudios Mayas, UNAM

ISSN: 0185-2574
} 
por Héctor Pérez Martínez (1938, doc. 4); después, obviamente una reproducción del documento anterior, por don Ángel María Garibay Kintana (1959: 168-170, doc. 4). Ambas publicaciones acusan deficiencias notorias. Los criterios paleográficos que hemos seguido aquí, son los siguientes:

Primero. Respeto absoluto al texto, excepto en aquellos casos en que la imprenta no puede reproducir ciertos signos gráficos. En el original, todas las $y$ griegas llevan un punto encima, como el de las jotas. Se apartan también del prototipo la distribución de los párrafos, los acentos y signos de puntuación.

Segundo. La transcripción desata todas las abreviaturas; pero, al hacerlo, usa corchetes franceses $(\diamond)$ para encerrar lo añadido. No recibió trato de abreviatura el acento largo (-) colocado sobre algunas vocales para significar $m \circ n$.

Tercero. Como el manuscrito no está foliado ni paginado, la transcripción usa sendas barras oblicuas $(/ / I I)$ para indicar el final de plana.

$\mathrm{Y}$, cuarto. Se puso especial cuidado en registrar las sigmas que, en ocasiones, el amanuense emplea a título de ese. Dicho registro va a ser posiblemente objetado por algunos lectores, ya que la carta de Landa se reproduce en forma facsimilar; pero, sin duda, será apreciado por los filólogos hispanistas. Impresas, las sigmas son más fáciles de detectar, y así su frecuencia y lugares de aparición.
Mis notas al pie de página, en fin, sólo empleadas para aclarar el texto de Landa, varias veces registran el año "1959". Es una referencia a la Relación de las cosas de Yucatán, edición de Ángel María Garibay, páginas 168-170.

\section{Epílogo}

El uso que he hecho de la carta de Landa (1578) es muy limitado. Su contenido se presta a un análisis y comentario mucho más amplios. Por ejemplo, mis páginas no examinan la función y significado que tienen los "scrúpulos" de Landa; su relación, tan íntima, con la actitud siempre autoapologética y defensiva del fraile. Tampoco ahondan en el "negocio" que se traía Landa con Santillán, ni magnifican el "ruydo" que se produjo entre él y el deán Miranda. Cuando el seráfico obispo chorrea infamia sobre el gobernador Las Casas, indicando de paso que era "hijo de padres de poco nombre", y todo para "descargo de mi consçiençia", ¿qué piadosos propósitos perseguía el buen fraile? Alguno de estos asuntos es inquietante. Todos, interesantes. Hasta el que atañe a su empleo de la noción de "consçiençia".

En cualquier caso, y para descargo de la mía, debo manifestar que mis páginas son las breves que corresponden a una simple presentación, sin la amplitud, erudición y profundidad que un estudio filológico o histórico exigiría. 
172

ESTUDIOS DE CULTURA MAYA, XXI

Tecel en mesoceo 4 de llarco

de 2578 .

Huy Iftes Sériones

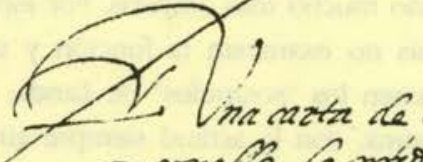

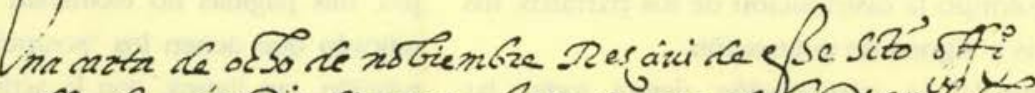

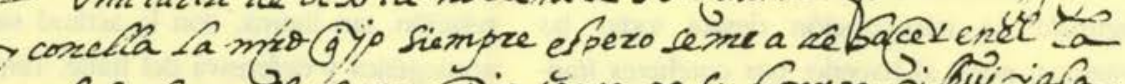

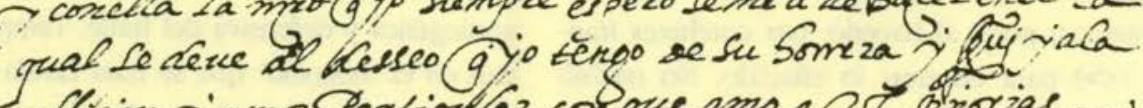

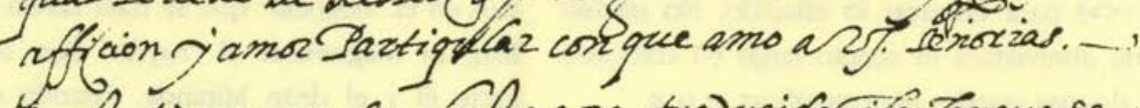

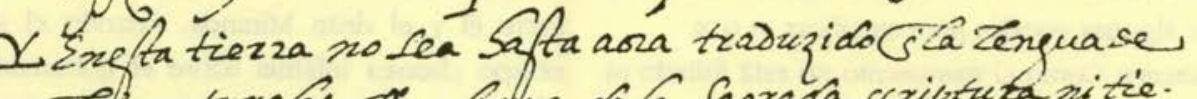
Lop naturales cospa afoura re la Sagracta scrivtuta nitie. nen en la Cenqua mes, Le sna Dobrina Existiana 9yo

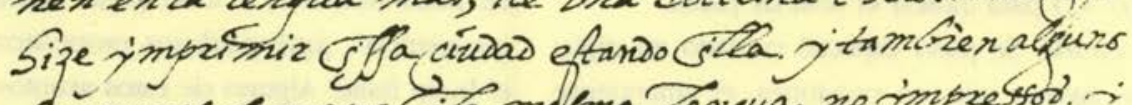

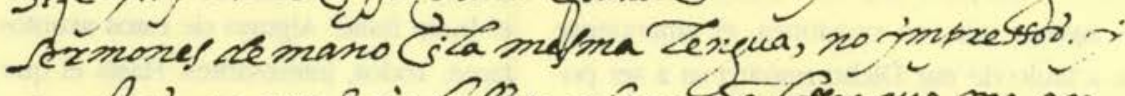
se tor por que ivio. Sallas aigunas ofras ake me an. sesfonterta o chalqunot, abia ja tids que corandaba Safieno recret pa examiñazlos jou fitienen $q$ resquitax. Sito que to a alo que sea cle aruertir a fos

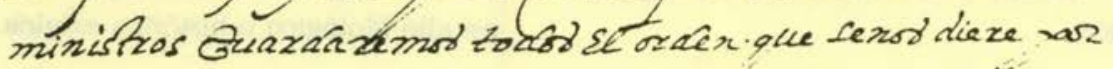
IrC que por aca arka ay es predicax cara uno conforme a ar riezcas que Gla enjua i Gia sufficier cia tiene

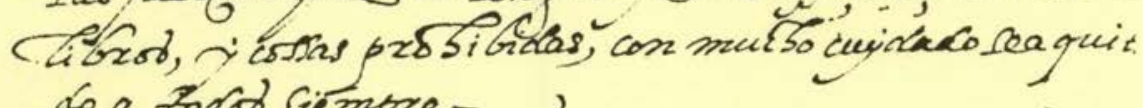
Lo a zodob siempze.

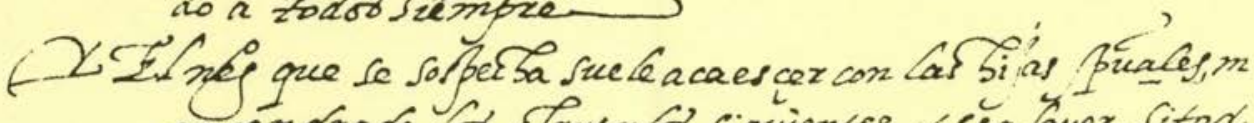
enpendrano for sfupulos figuientes, I sia faucx, fitod. rija put, aurque hrs sca ceel sacramento re la beritencia

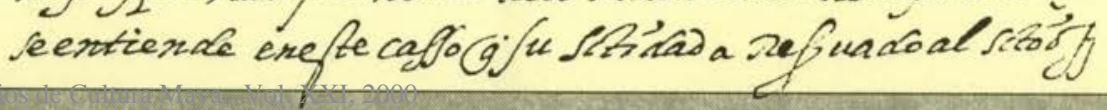

Instituto de Investigaciones Filologica
Centro de Estudios Mayas, UNAM ISSN: 0185-2574 


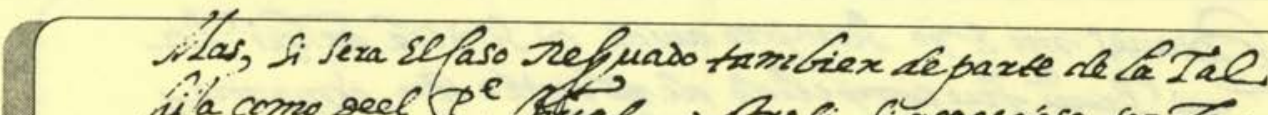

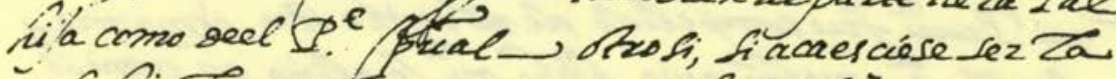

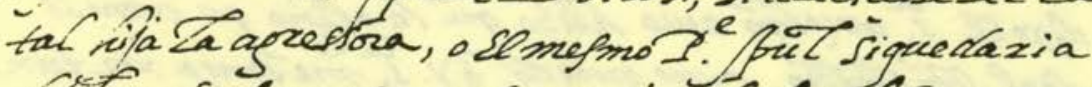

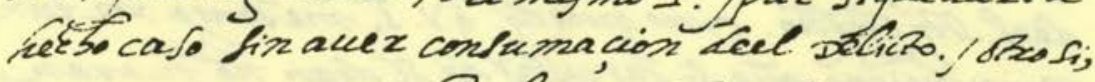

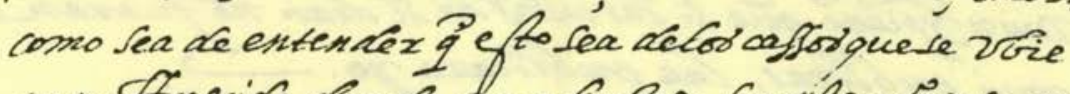

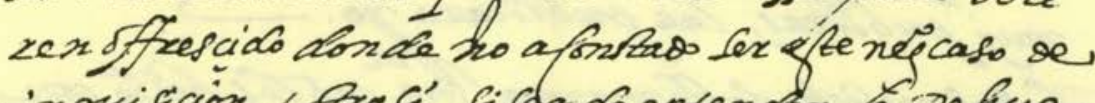

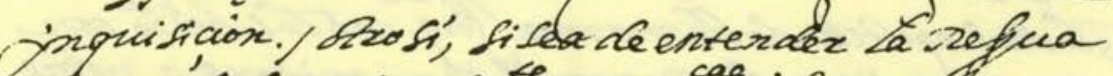

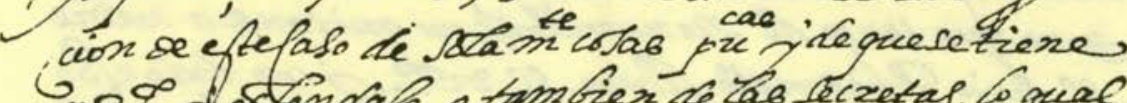

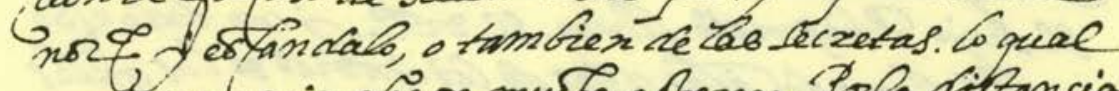

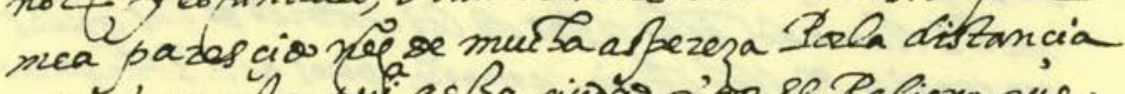

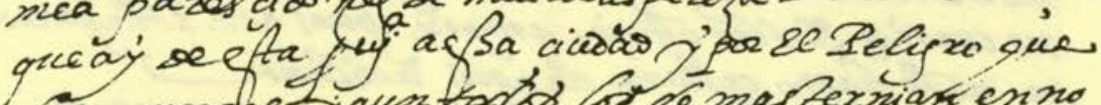

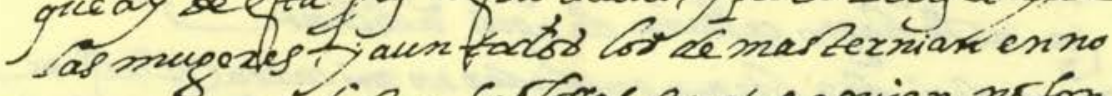

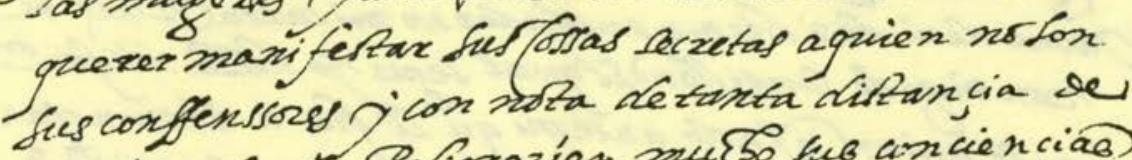
camino donder Peligrazían mulbo fub ancienciä) se tods efto supp a V.S. Seme de Raviars yise

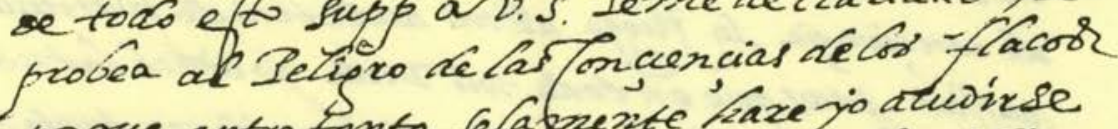

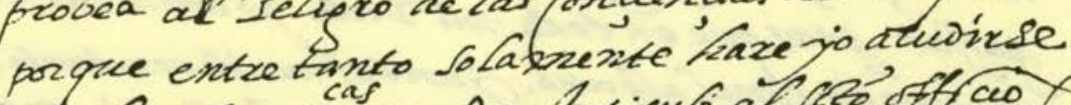

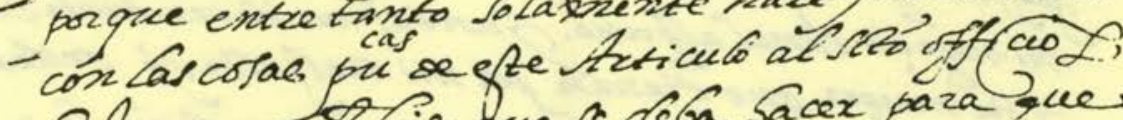

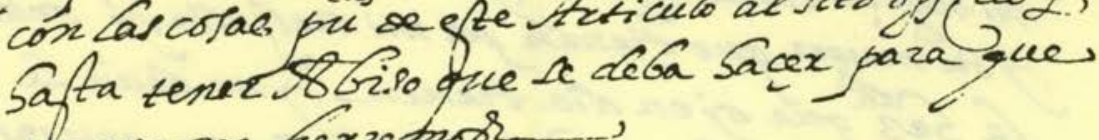
por aca no herzetroor...,

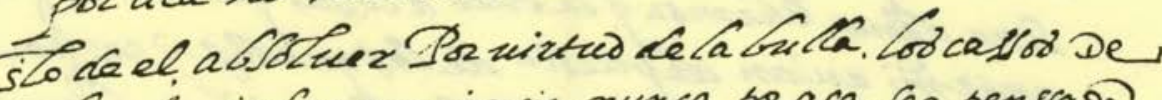
nezelia inforo conciencig, nuxca poraca lea penssaro)

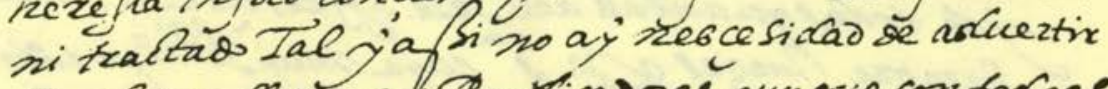

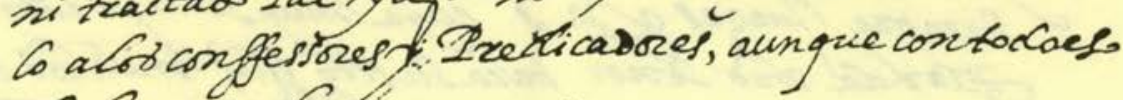

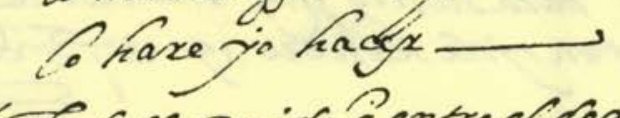

Vlsto de sC zuydo à entue el dean yimi apusaso le bipo \&C inc yo, pues, como 2 . S. dipe, fiendo fus culastan

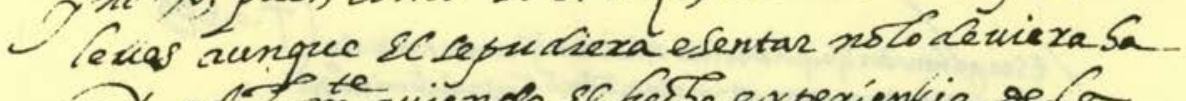
(ca espi m auiendo SE habo expexientia re La

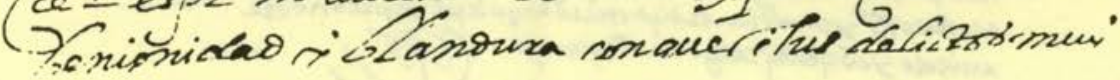




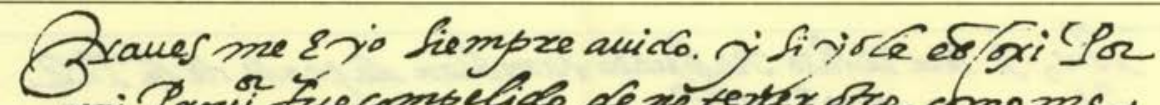

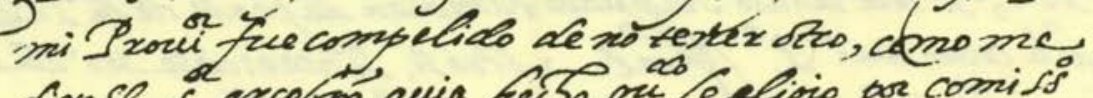
divose s, arcobó auia herbo qu le eligio por comis is

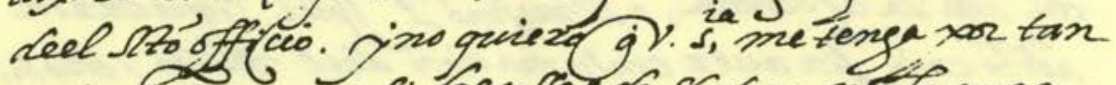

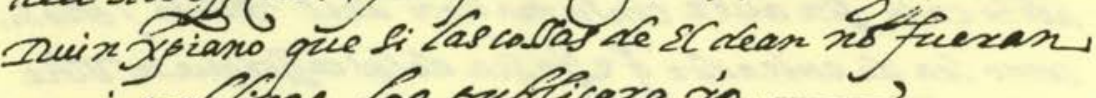
muy sublicas, las publicaza yo.

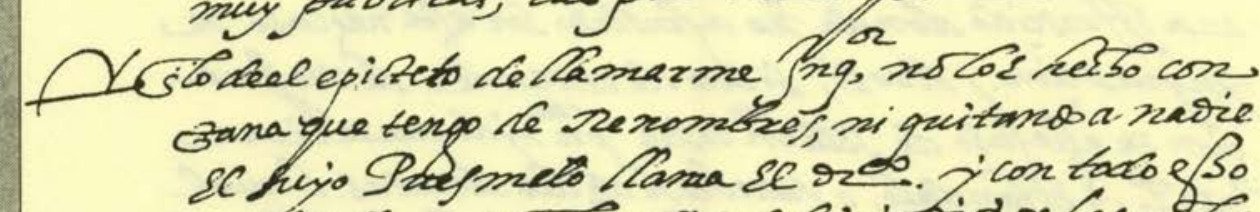

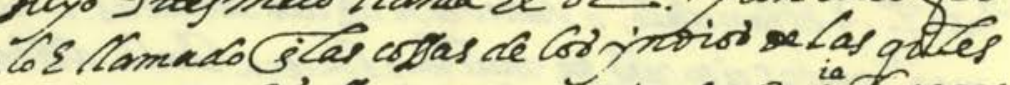

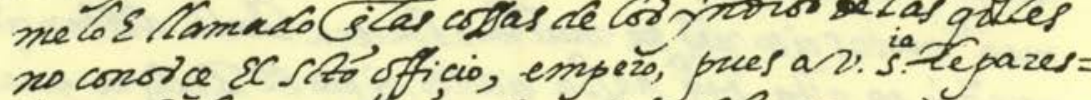
no conotice SC sto officio, empers, pres a 2. S. Lepazes= (ce note hapa, cessaza de aqui adelante

Vome Leui dax biex a entendexen mi caxta sixif oc,

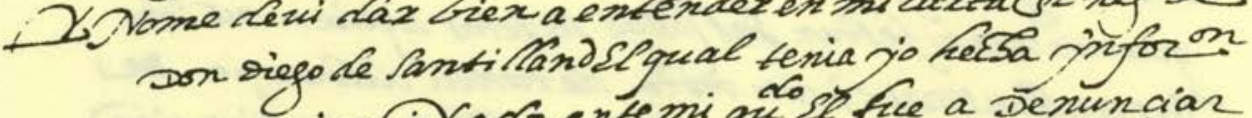

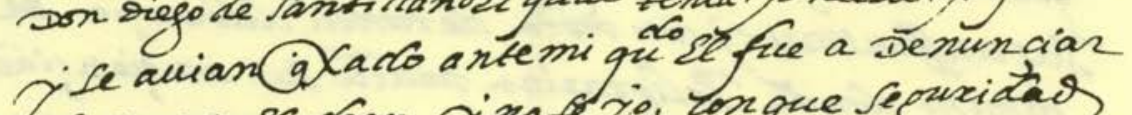

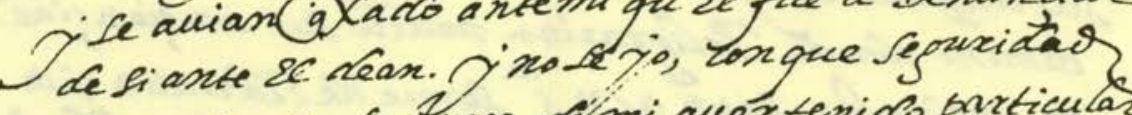
Leconciencia le turga demi aueztenicls particular. pafion pres que en toda mi viata jo cotrel lature ningeo cio conel afjuno. diante mo ievertanto se isu muger que tieners for mi zelperto of raten.

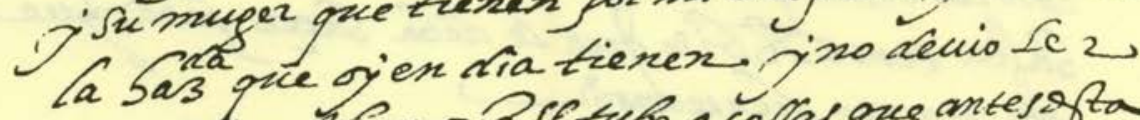

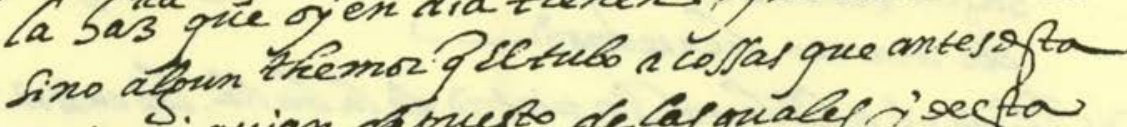

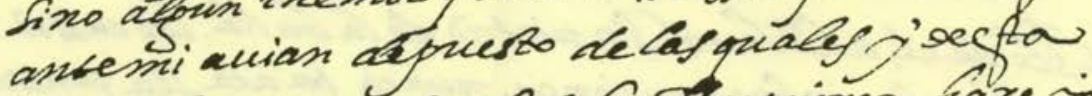

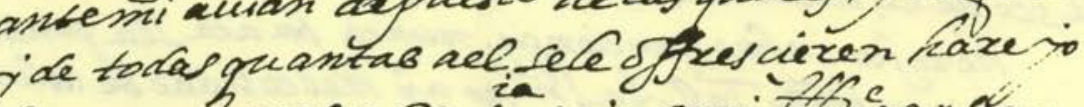

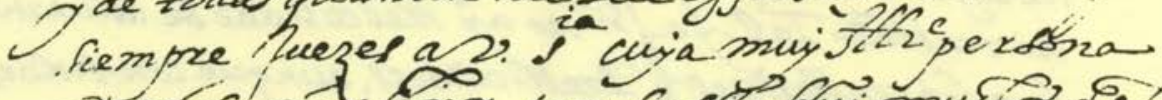

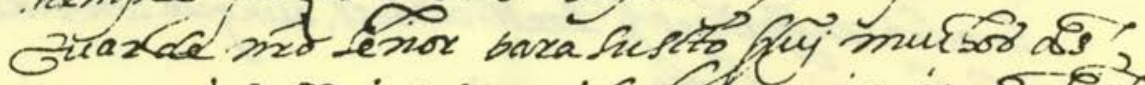

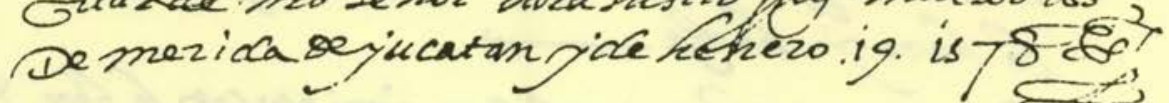
Gerav. S. Irsmanos.

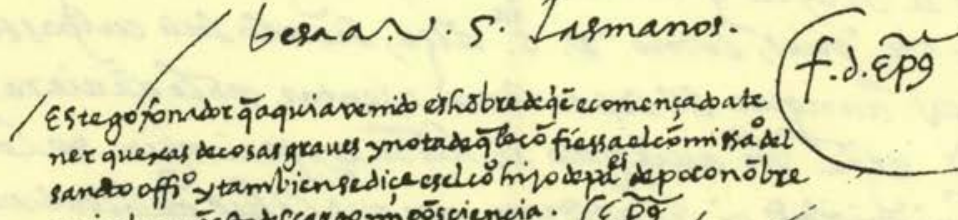

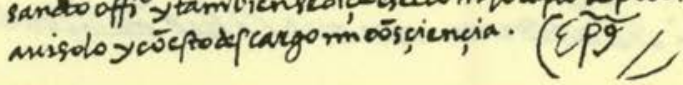


ESCRITOS MAYAS INÉDITOS Y PUBLICADOS HASTA 1578

175

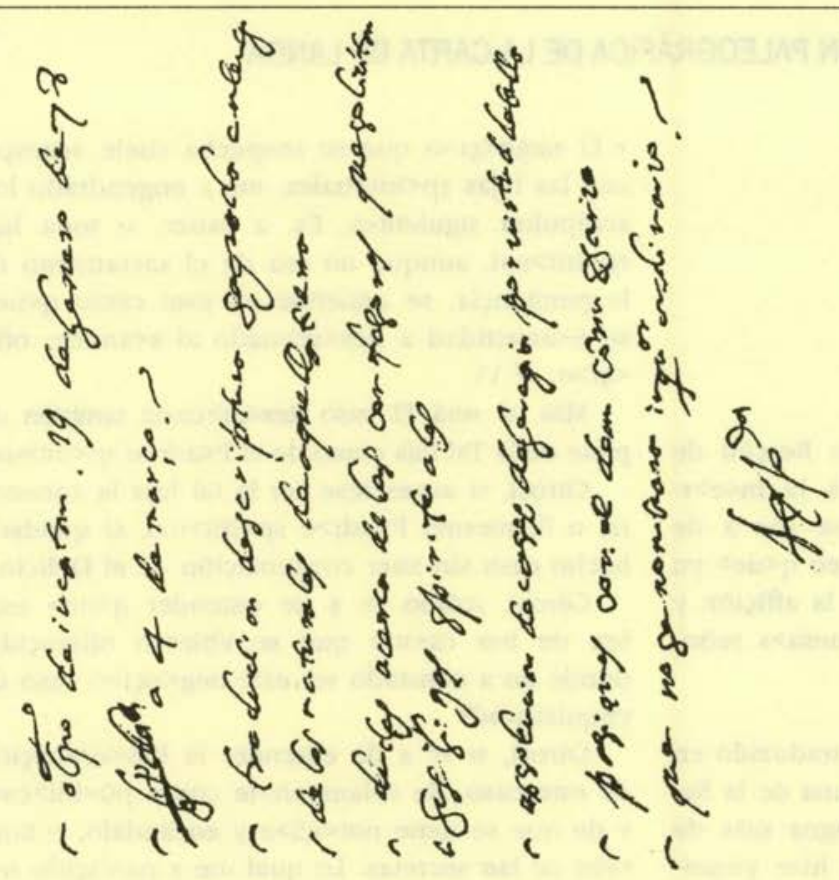

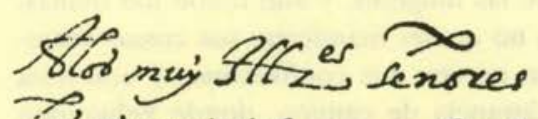

2 inquistickes apostorticos delar Truena

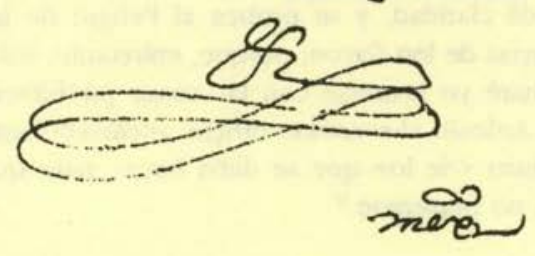

Instituto de Investigaciones Filológicas/

Centro de Estudios Mayas, UNAM

ISSN: 0185-2574

http://www iifilologicas unam mx/estculmaya/ 


\section{TRANSCRIPCIÓN PALEOGRÁFICA DE LA CARTA DE LANDA}

Reçe $<u i>d a$ en México

4 de Março de $1578^{5}$

Muy Ill<ust>res señores

$r$ Vna carta de ocho de nobiembre Resçiuí de esse $s<a n>c t o$ offi $<c ̧>$ io. y con ella la $m<e>r$ $<$ çe $>$ d q<ue $>$ yo siempre espero se me a de haçer en él, ${ }^{6}$ la qual se deue al desseo q<ue> yo tengo de su honrra serui $<$ çi>o, y a la affiçión y amor Partiqular con que amo a $v<$ uesa $>$ s señorías.

$r$ En esta tierra no se a, hasta aora, traduzido en la lengua de los naturales cossa alguna de la Sagrada scriptura, ni tienen en la lengua más de vna doctrina Cbristiana, $\mathrm{q}<\mathrm{ue}>$ yo hize ymprimir en essa çiudad, estando en ella, ${ }^{7}$ y también algunoo sermones de mano en la mesma lengua, no ympressoo; y de esto $\sigma$, porque $\mathrm{E}$ yo hallado alguna $\sigma$ cossa $\sigma$ que me an descontentado en algunoo, abía ya días que loo andaba haziendo Recoxer $\mathrm{p}<\mathrm{ar}>\mathrm{a}$ examinarloo $\mathrm{y}$ ver si tienen $q<u e>$ leo quitar.

$\mathrm{Y}$, en lo que toca a lo que se a de aduertir a loo ministros, guardaremos todos $\mathrm{El}$ orden que se noo diere; porq<ue>, El que por acá aora ay, es predicar cada vno conforme a la $\sigma$ fuerça $\sigma$ que en la lengua y en la suffiçiençia tiene. Libroo, y cossas prohibidas, con mucho cuydado se a quitado a todoo siempre. $r$ El nego<çi>o que se sospecha suele acaesçer con las hijas $s p<i r i t>$ uales, me a engendrado loo scrúpuloo siguientes: Es, a sauer, si toda hija $\mathrm{sp}<$ irit>ual, aunque no sea de el sacramento de la penitençia, se entiende en este casso $q<u e>$ su $\mathrm{S}<$ an $>$ ctidad a Res<er $>$ uado al $\mathrm{s}<$ an $>$ cto offi$<$ çi>o. // II

Más, si será El caso Res<er>uado también de parte de la Tal hija como de el $\mathrm{P}<\mathrm{adr}>\mathrm{e}$ sp<irit>ual.

Otrosí, si acaesçiese ser la tal hija la agressora, o El mesmo $\mathrm{P}<\mathrm{adr}>\mathrm{e}$ sp<irit>ual, si quedaría hecho caso sin auer consumaçión de el Delicto.

Otrosí, ¿cómo se a de entender q<ue> esto sea de loo cassoo que se vbieren offresçido, donde no a constado ser este neg<oçi >o caso de ynquisiçión? ${ }^{8}$

Otrosí, si se a de entender la Res<er>uaçión de este caso, de solam<en>te cosa $\sigma$ pú<bli $>$ ca $\sigma$, y de que se tiene not<içi >a y eocándalo, o también de la secretas. Lo qual me a paresçido ne$\mathrm{g}<\mathrm{oçi}>0$ de mucha aspereza, Por la distançia que ay de esta $\mathrm{p}<\mathrm{ro}>\mathrm{u}<\mathrm{inç}>\mathrm{ja}$ a essa çiudad $\mathrm{y}$ por $\mathrm{El}$ Peligro que las mugeres, y aun todoo loo demás, ternían en no querer manifestar sus cossas secretas a quien no son sus conffessores, y con nota de tanta distançia de camino, donde Peligrarían mucho suo conçiençia

De todo esto, supp $<\mathrm{li}>\mathrm{co}$ a $v<$ uesa $>\mathrm{s}<\mathrm{eñor}>\mathbf{i} a$ se me dé claridad, y se probea al Peligro de las

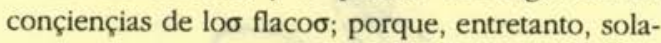
mente haré yo acudirse con las cosa pú<bli>cas de este Artículo al $s<a n>$ cto offiçio, $s<$ cilicet $>$ hasta tener abiso <de lo> que se deba haçer, para que por acá no herremoo. ${ }^{9}$

\footnotetext{
${ }^{5}$ Esta inscripción, cronológicamente posterior a la carta, fue puesta en México a título de recibo.
}

${ }^{6} 1959:$ "...y con ella la merced que siempre espero se me a de hacer en la qual se deve al deseo..."

7 "On December 15, 1574, Bravo made a full report of this affair to Governor Velásquez de Gijón. The latter formally received 'the settlement and land of Chiuoha' under the protection of the Crown and promised to see that the Indians received religious instruction. A few days later the matter was brought to the attention of Lic. Cristóbal de Miranda, dean of the cathedral church of Mérida and administrator of the diocese in absence of Bishop Landa <who> was in Mexico City at this time" (Scholes y Roys, 1968: 224, nota 6). Sobre la Doctrina christiana publicada por Landa en México, véase García Icazbalceta (1954: 485, n. 38) y Zulaica Gárate (1991: 177, n. 52).

${ }^{8}$ 1959: "otro si, como se a de entender que esto sea de los cassos que se uvieren ofrescido donde no a constado ser este negocio caso de ynquisizion".

9 1959: "...porque entretanto solamente hare yo acudirse con las cosas publicas de este Articulo al Santo

Officio en hasta tener abiso que se deba hazer para que por aca no herremos".
Estudios de Cultura Maya. Vol. XXI, 2000 .

Instituto de Investigaciones Filológicas/

Centro de Estudios Mayas, UNAM 
$r$ En lo de absoluer Por uirtud de la bulla loo casso $\sigma$ De herejía in foro conçiençiae, ${ }^{10}$ nunca por acá se a penssado ni tractado Tal, y, assí, no ay neoçesidad de aduertirlo a loo conffessores y Predicadores; aunque, con todo eso, lo haré yo haçer. ${ }^{11}$

$r$ En lo de El Ruydo q<ue> entre el deán y mí a pasado, ${ }^{12}$ le hizo Él y no yo. Pues, como v<uesa> $s<$ eñor>ía dize, siendo su $\sigma$ culpas tan leues, aunque Él se pudiera esentar, ${ }^{13}$ no lo deuiera haçer esp<iritua $>\operatorname{lm}<$ en $>$ te, auiendo Él hecho experiençia de la benignidad y blandura con que, en sus delictos muy // $/ 1$ graues, me E yo siempre auido. Y, si yo le eocoxí Por mi Proui<s $>$ or, fue compelido de no tener otro, como me dixo El $s<$ eñ>or arçob<is>po auía hecho qu<an>do le eligió por comiss $<$ ari $>0$ de el $s<a n>c t o$ offiçio. $\mathrm{Y}$ no quiero $\mathrm{q}<\mathrm{ue}>\mathrm{v}<\mathrm{uesa}>\mathrm{s}<\mathrm{eñor}>$ ía me tenga por $\tan$ Ruin chr<ist>iano que, si las cossas del El deán no fueran muy públicas, la $\sigma$ publicara yo.

$r$ En lo de el epícteto de llamarme "Inq<uissi$\mathrm{d}>$ or", no lo E hecho con gana que tengo de Renombres, ni quitando a nadie $\mathrm{El}$ suyo, pues me lo llama el $\mathrm{d}<\mathrm{e}>\mathrm{r}<\mathrm{ech}>0$. Y, con todo esso, me lo E llamado en las cossas de loo yndioo, de las quales no conooçe El $\mathrm{s}<\mathrm{an}>\mathrm{cto}$ offiçio; empero, pues a $v<$ uesa $>s<e n ̃ o r>i a$ le paresçe no se haga, çessará de aquí adelante. $r$ No me deuí dar bien a entender en mi carta en el neg<oçi>o de Don Diego de Santillân, ${ }^{14} \mathrm{dEl}$ qual tenía yo hecha ynfor<maçi $>$ ón y se auían q<ue $>$ xado ante mí, qu<an>do Él fue a Denunçiar de sí ante El deán. Y no sé yo con qué seguridad de conçiençia se Juzga de mí auer tenido particular passión, pues que, en toda mi vida, yo con él la tube, ni negoçio con él alguno. Y, antes, me deuen tanto Él y su muger, que tienen, por mi Respecto y orden, la haz<ien $>$ da que oy en día tienen. Y no deuió ser sino algún themor q<ue> Él tubo a cossas que antes ésta ante mí auían depuesto, de las quales, y de ésta y de todas quantao a él se le offresçieren, haré yo siempre Juezes a v<uesa $>\mathrm{s}<$ eñor $>\mathrm{ia},{ }^{15}$ cuya muy $\mathrm{Ill}<$ ust $>$ re persona guarde $n<$ uest $>$ ro Señor para su $s<a n>c t o$ $s<$ er $>$ ui $<$ çi $>0$ muchoo años.

De Mérida de Yucatán, y de henero 19, 1578 años. ${ }^{16}$

Besa a $\mathbf{v}<$ uesa $>\mathrm{S}<$ eñoría $>$ las manos,

$$
\mathrm{f}<\text { rater }>\mathrm{d}<\text { idacus }>, E p<i s c o p u>\sigma \text { (rúbrica) }
$$

Este gov<er $>$ nador $q<$ ue $>$ aquí a venido, es hombre de $\mathrm{q}<\mathrm{u}>$ ien e començado a tener quexas de cosas graues, y nota de $q<u e>$ le confiessa el commissa $<$ ri $>0$ del sancto offi $<$ çi $>0$. Y también se diçe es él co<noçid $>0$ hijo de $p a<d r>e s$ de poco nombre. Auísolo y, con esto, descargo mi consçiençia. ${ }^{17}$

${ }^{10}$ 1959: "En lo de absolver Por virtud de la bulla los cassos de herejia infoco conciencie..."

${ }^{11} 1959$ : "...no ay necesidad de advertirlo a los conffesores y predicadores, aunque con todo eso lo hare".

${ }^{12} \mathrm{Al}$ parecer, se trataba del licenciado Cristóbal de Miranda (véase Scholes y Roys, 1968: 224), quien fue deán de la catedral de Mérida hasta después de fallecer Landa.

${ }^{13}$ 1959: "...aunque El se pudiera asentar..."

${ }^{14}$ Diego de Santillán había sido gobernador de Yucatán entre marzo de 1571 y septiembre de 1573 . Casó con doña Beatriz de Montejo, viuda de Francisco Montejo, el sobrino, en octubre de 1572. Landa, que llegó tarde a la cita un año después, deseaba que su sobrino contrajera nupcias con doña Beatriz. La relación geográfica de Santillán puede consultarse en el tomo primero de las Relaciones bistórico-geográficas de la Gobernación de Yucatán (1983: 395-402).

15 1959: "...themor que el tubo a cosas que antes desta ante mi avian depuesto de los quales y desta y de todas quantas a el se le ofrecieron are yo siempre juezes a Vuestra Señoria..." Obsérvese la discordancia del tratamiento singular, "vuesa Señoría", cuando es evidente que el autor se refiere a los "illustres señores Inquisidores" de Nueva España y, aquí, a los que reconoce por "Juezes".

${ }^{16}$ Hasta aquí, la caligrafia del amanuense de oficio. Lo que sigue, y el post scriptum, es de la propia mano de Landa.

${ }^{17} 1959$ : “...y nota de que le confiessa a el comissario del Santo Officio y tambien se dize es el conocido hijo de padres de poco nombre aviselo y con esto descargo mi conciencia.- Fray Diego.- Episcupus".

Instituto de Investigaciones Filológicas/

Centro de Estudios Mayas, UNAM 
Ep<iscopu $>6$ (rúbrica)

\section{$1 / 11$}

\section{[SOBRESCRITO:]}

A loo muy Ill<ust>res señores

Los ynquisidores apostólicos

de la Nueua Es<pañ>a

Méx $<\mathrm{i}>\mathrm{co}$.-

\section{[EXCERPTA AL DORSO DEL SOBRESCRITO:]}

$r$ ob<is>po de iucatán 19 de henero de 78

$r$ rr<esçiui $>$ da a 4 de março

$r$ traductión de scriptura sagrada en lengua de los naturales de aquella tierra

$r$ dudas açerca de los confesores que soliçitan sus hijas spirituales

$r$ absolución de cosas de heregía por uirtud de bulla

$r$ pasiones con el deán commissario

$r$ que no se nombrará inqu<isid $>$ or ordinario

Ar $<$ çobis $>$ p $<$ a $>$ do

\section{Bibliografia}

Advertencia: Un asterisco $\left(^{*}\right)$ frente a la entrada significa que el documento, su contenido o su descripción, son conocidos sólo por referencias.

Manuscritos

Carta

1578 Diego de LANDa a los Inquisidores Apostólicos de la Nueva España, enero 19, $\mathrm{GN}$, ramo Inquisición, vol. 90, exp. 42 (antes 8).

LANDA, DIEGo DE

1566 [Relación de las cosas de Yucatän,] Fray $D i^{\circ}$ de oLanda/ M D LXVI, copia manuscrita en la Biblioteca de la Real Academia de la Historia, Madrid, bajo signatura [24-B-68] 9-27-2/5153.

\section{Publicaciones}

\section{Ciudad Real, Antono de}

1984 Calepino maya de Motul, México, unam, Instituto de Investigaciones Filológicas, Filología, Gramáticas y Diccionarios, 2, texto facsímil, 2 tomos, edición de rené acuña.

CORONEL, JUAN

1620 Arte en la lengua de maya, México, Emprenta de Diego Garrido, por Adriano César.

1620 Doctrina Christiana en lengua de maya, recopilada y enmendada por... México, Emprenta de Diego Garrido, por Cornelio César.

1620 Discursos predicables, con otras diuersas materias Espirituales..., recopilados y enmendados por... México, Imprenta de Diego Garrido, por Pedro Gutiérrez.

\section{- Doctrina}

1575 Doctrina Christiana en lengua de maya, México: $<$ Casa de Pedro Balli $>$.

Garcí Icazbalceta, Joaquín

1954 Bibliografia mexicana del siglo xV, México, Fondo de Cultura Económica, nueva edición, por Agustín Millares Carlo.

Gabriel. de San Buenaventura

1996 Arte de la lengua maya, México, unмm, Instituto de Investigaciones Filológicas, Centro de Estudios Mayas, Fuentes para el Estudio de la Cultura Maya, 13. Incluye facsímil (1684), edición de René Acuña.

Garibay Kintana, Ángel Marí (editor)

1959 Relación de las cosas de Yucatân, de Diego de Landa, México, Editorial Porrúa (Biblioteca Porrúa, 13).

LEÓN RIVERA, JORGE DE

1996 "Un Arte de la Lengua Mexicana escrito en Milpa Alta denunciado ante la Inquisición...", 
Estudios de Cultura Nábuatl, vol. 26: 245252.

Lizana, Bernardo de

1633 Historia de Yvcatan... Valladolid, Gerónimo Morillo, Biblioteca Nacional de Madrid, R/ 5925.

1995 Devocionario de Nuestra Señora de Izamal..., México, unam, Instituto de Investigaciones Filológicas, Centro de Estudios Mayas, Fuentes para el Estudio de la Cultura Maya, 12, edición de René Acuña.

López de Cogolludo, Diego

1688 Historia de Yucathan..., Madrid, Juan García Infanzón, consultada en la edición facsimilar de México, 1957; véase Jorge Ignacio Rubio Mañé, 1957.

-Medina, Toribio

1907 La imprenta en México (1539-1821), Santiago de Chile, 8 volúmenes.

-Pérez Martínez, héctor (editor)

1938 Relación de las cosas de Yucatán, por fray Diego de Landa, México, Editorial Pedro Robredo.

\section{Relaciones}

1983 Relaciones bistórico-geográficas de la Gobernación de Yucatán, 2 tomos, México, UNaM, Instituto de Investigaciones Filológicas, Centro de Estudios Mayas, Fuentes para el Estudio de la Cultura Maya, 1.

RUBIO MAÑE, JORGE IGNACIO

1957 "Prólogo" a la edición de la Historia de Yucathan, de Diego López de Cogolludo, México, Editorial Academia Literaria. La obra se publicó en dos volúmenes.

Scholfs, France V., y Ralph L. Roys

1968 The Maya Cbontal Indians of Acalan-Tixchel..., Norman, University of Oklahoma Press. The Civilization of the American In- dian Series, 91. Con la colaboración de Eleanor B., Adams y Robert S. Chamberlain. [Hay traducción al español: unam, México, 1996.]

Tozzer, Alfred M. (editor)

1941 Landa's Relación de las cosas de Yucatân, Cambridge, Massachusetts, Publicado por el Museo, Papers of the Peabody Museum of American Archaeology and Ethnology, Harvard University, volumen XVIII, traducción editada con notas.

1977 A Maya Grammar, Nueva York, Dover Publications ( $1^{3}$ edición, Cambridge, Mass., 1921. Vol. IX de los Peabody Museum Papers.)

Varea, Francisco de

1699 Calepino en lengua cakchiquel, Ms. 497.43, $\mathrm{N}^{2}$ V42, en la American Philosophical Society de Filadelfia. Es copia de mano de fray Francisco Cerón.

VÁzQuez, Francisco

1937 Crónica de la Provincia del Santísimo Nombre de Jesuis de Guatemala, Guatemala, Sociedad de Geografia e Historia. Biblioteca "Goathemala", vol. XIV, tomo primero, con prólogo, notas e índices por Lázaro Lamadrid.

-WAGNer, EnRIQue R.

1946 Nueva bibliografia mexicana del siglo xv, México, Suplemento a las bibliografias de don Joaquín García Icazbalceta, don José Toribio Medina y don Nicolás León, traducida por Joaquín García Pimentel y Federico Gómez de Orozco.

Zulaica Gárate, Romín

1991 Los franciscanos y la imprenta en México en el siglo Xvi, México, unмM, Instituto de Investigaciones Bibliográficas, primera edición facsimilar. 